\title{
Analisis Pengaruh Laju Aliran Massa Fluida Terhadap Perubahan Temperatur Pada Radiator Honda CBR 150 CC
}

\section{Analysis of the Effect of Fluid Mass Flow Rate on Temperature Changes in the Honda CBR 150 CC Radiator}

\author{
Rihaldi Syahputra ${ }^{1}$, Armila ${ }^{2 *}$, Rudi Kurniawan Arief ${ }^{3}$ \\ 1,2*,3 Program Studi Teknik Mesin, Fakultas Teknik, Universitas Muhammadiyah Sumatera Barat \\ 1,2*,3 Aur kuning, Jl. By Pass, Tarok Dipo, Kec. Guguk Panjang, Kota Bukittinggi, Sumatera Barat \\ *Email: kimmylala74@gmail.com \\ *Koresponden Email: kimmylala74@gmail.com
}

Artikel dikirim: 09/09/2021

Artikel direvisi: 21/10/2021

Artikel diterima: 26/10/2021

\begin{abstract}
Abstrak. Kehandalan unit kendaraan bermotor ditentukan 4 hal, diantaranya: sistem pendingin, sistem bahan bakar, sistem pelumasan, sistem pemasukan udara dan gas buang. Dari ketiga sistem tersebut yang mempunyai potensi besar terhadap keandalan kendaraan bermotor adalah sistem pendingin. Proses pembakaran diruang bakar akan menimbulkan panas, dan panas tersebut diserap oleh coolant radiator dan jika air radiator panas akan merusak komponen engine. Tujuan dari penelitian ini melakukan analisis laju aliran fluida terhadap perubahan temperatur untuk menentukan akar penyebab. Adapun metode berbentuk eksperimen yaitu mengetahui pengaruh laju aliran massa fluida, perubahan temperatur fluida masuk dan kapasitas radiator Honda CBR 150 CC. Hasil dari pengumpulan data diperoleh putaran mesin dari 8000, 8500, 9000, 9500 dan $10000 \mathrm{rpm}$ dalam waktu yang divariasikan dari 1 menit sampai 3 menit dengan temperatur masuk $\left(\mathrm{T}_{\text {in }}\right) 90^{\circ} \mathrm{C}, 100^{\circ} \mathrm{C}$, dan $110^{\circ} \mathrm{C}$. Hasil dari analisa dalam waktu 3 menit pada putaran $8000 \mathrm{rpm}$ didapatkan laju aliran perpindahan panas $\left(\mathrm{Q}_{\text {in }}\right) 9185400$ watt terjadinya kenaikan temperatur dalam putaran 10000 rpm dengan $\left(Q_{\text {in }}\right) 22680000$ watt sedangkan waktu 3 menit pada putaran 8000 rpm didapatkan laju aliran perpindahan panas ( $\left.\mathrm{Q}_{\text {out }}\right)$ 185887133,8 watt terjadinya kenaikan temperatur dalam putaran $10000 \mathrm{rpm}$ dengan $\left(\mathrm{Q}_{\text {out }}\right)$ 230977553,5 watt.
\end{abstract}

Kata kunci: Fluida, Perpindahan panas, Radiator, Temperatur

Abstract. The reliability of motorized vehicle units is determined by 4 things, including: cooling system, fuel system, lubrication system, air intake system and exhaust gas. Of the three systems that have great potential for the reliability of motorized vehicles is the cooling system. The combustion process in the combustion chamber will generate heat, and the heat is absorbed by the radiator coolant and if the radiator water is hot it will damage the engine components. The purpose of this research is to analyze the fluid flow rate to temperature changes to determine the root cause. The experimental method is to determine the effect of the mass flow rate of the fluid, changes in the inlet fluid temperature and the capacity of the Honda CBR 150 CC radiator. The results of data collection obtained engine speed of 8000,8500, 9000, 9500 and 10000 rpm in time varied from 1 minute to 3 minutes with inlet temperatures (Tin) $90^{\circ} \mathrm{C}, 100^{\circ} \mathrm{C}$, and $110^{\circ} \mathrm{C}$. The results of the analysis within 3 minutes at 8000 rpm rotation obtained a heat transfer flow rate (Qin) of 9185400 watts an increase in temperature at 10000 rpm rotation with (Qin) 22680000 watts while for 3 minutes at 8000 rpm the heat transfer flow rate (Qout) was obtained. 185887133.8 watts the increase in temperature in 10000 rpm rotation with (Qout) 230977553.5 watts.

Keywords: Fluid, Heat Transfer, Radiator, Temperature.

JTTM: Jurnal Terapan Teknik Mesin is licensed under a Creative Commons Attribution-NonCommercial 4.0 International License.. 
Analisis Pengaruh Laju Aliran Massa Fluida Terhadap Perubahan Temperatur Pada

Radiator Honda CBR 150 CC

\section{PENDAHULUAN}

Pemakaian kendaraan bermotor yang menggunakan bahan bakar bensin, akan menghasilkan panas dan proses pembakarannya diiringi dengan pembebasan panas. Panas yang dihasilkan diserap oleh liner, kemudian diserap oleh coolant, atau sirip body silinder untuk dibuang panas melalui kedua komponen tersebut[1][2]. Hal ini bertujuan agar proses pembakaran bekerja dengan maksimal dan menghasilkan tenaga yang sempurna. Jika sistem pendingin menggunakan air (udara) atau coolant mengalami kendala maka akan mempengaruhi kinerja dari kendaraan itu sendiri [3][4][5].

Radiator mempunyai peran yang cukup penting dalam proses pendinginan pada kendaraan roda dua (motor) maupun roda empat (mobil), dimana sistem pendingin tersebut menggunakan coolant sebagai media pendingin[6][7]. Keterkaitan dengan efisiensi bahan bakar yang ada kaitannya dengan sistem pendingin cukup besar pengaruhnya[8]. Jika kendaraan bermotor mesin dalam kondisi panas, baik disebabkan oleh mesin itu sendiri maupun sistem yang lain[9], akan mengakibatkan borosnya bahan bakar. Coolant radiator berfungsi untuk menyerap panas dari proses pembakaran, panas oli[10].

Analisis terhadap laju aliran fluida semakin tinggi nilai perpindahan panas yang diperoleh dalam suatu pengujian[11], nilai laju aliran mempunyai pengaruh terhadap pelepasan panas fluida dari radiator[3][12]. Makin besar laju aliran massa pada refrigerant, maka akan berpengaruh terhadap makin besar koefisiensi perpindahan panas rata-rata yang terjadi pada pipa kapiler[13]. Penelitian laju aliran fluida pada mobil berkapasitas 1300 CC koefisiensi perpindahan panas sisi luar radiator dipengaruhi oleh laju aliran massa fluida dan temperatur permukaan radiator[3][14].

Penelitian ini berbentuk eksperimen. Tujuan dalam penelitian ini adalah menganalisis laju aliran fluida pada kendaraan bermotor CBR 150CC, untuk mengetahui efisiensi bahan bakar yang dipergunakan sistem pendinginan mesin Honda CBR 150 CC.

\section{METODE.}

Metode penelitian yang dipergunakan sesuai dengan diagram alir pada gambar 1. 1). Langkah pertama mulai dari persiapan alat kerja maupun alat bantu untuk persiapan dilakukan pengujian, 2). Pemasangan alat uji ini dipergunakan untuk mengetahui performa yang dibutuhkan dalam hal penelitian, 3). Pengambilan data dari hasil pengujian untuk dilakukan analisis terhadap kendaraan bermotor Honda CBR 150 CC, 4). Analisis data yang didapat berdasarkan alat uji yang dipergunakan.

A. Waktu dan tempat penelitian.

Penelitian ini dilakukan antara Bulan Juni-Agustus 2021 dan dilaksanakan ditempat Klinik Engine, Jl. Jambu Air No.254, Taluak Ampek Suku, Banuhampu, Kabupaten Agam, Sumatera Barat.

B. Alat dan bahan digunakan selama penelitian

Pada penelitian ini menggunakan alat dan bahan untuk mendapatkan data yang akurat.

1) Kunci ring pas

2) Obeng 

3) Kunci L
4) Kunci $T$
5) Pressure gauge
6) Temperatur Digital
7) Stopwatch
8) Motor HONDA CBR $150 \mathrm{CC}$
9) Coolant merk HONDA AHM

10) Selang radiator

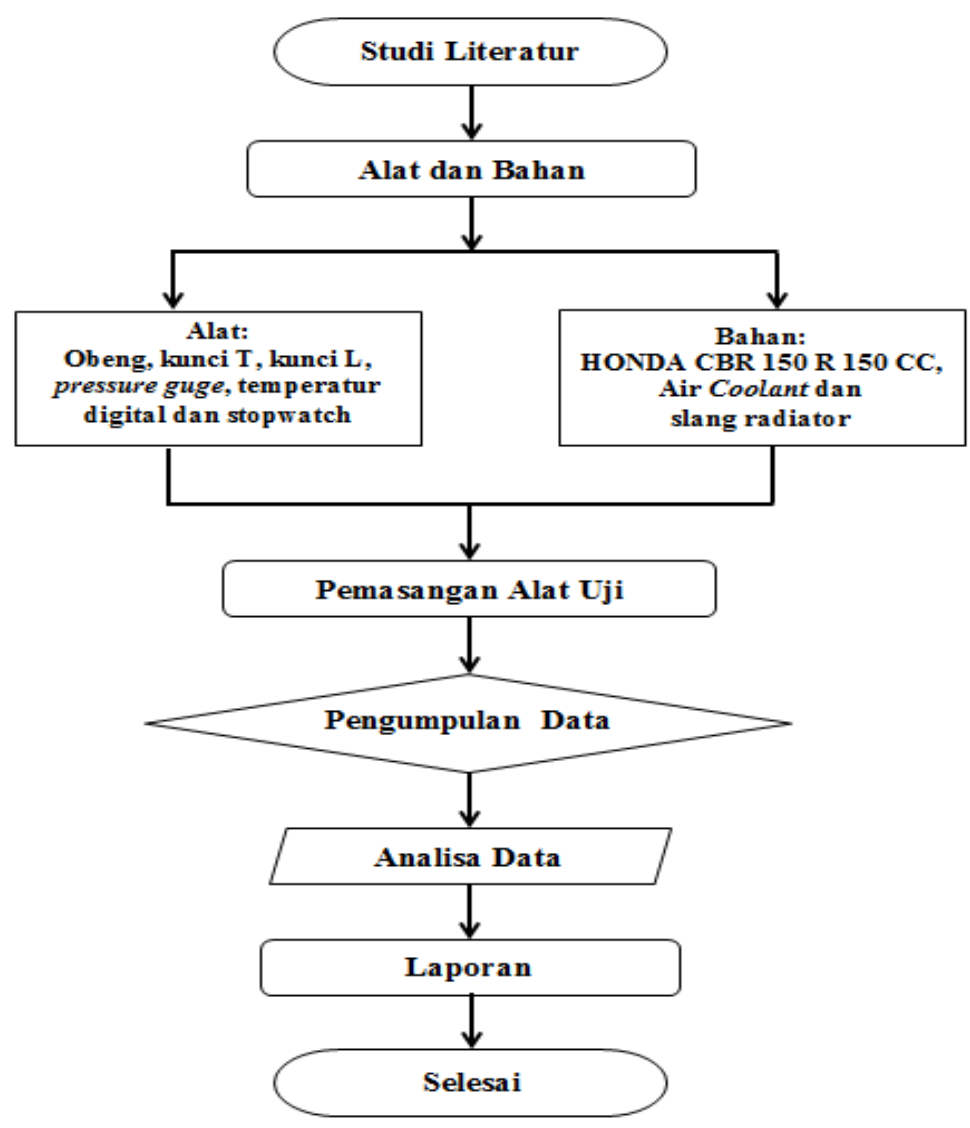

Gambar 1. Diagram alir penelitian yang dilakukan.

C. Langkah-langkah penelitian

Untuk penelitian pengaruh laju aliran massa fluida dan temperatur fluida masuk terhadap kapasitas radiator[3][15] pada sistem pendinginan mesin Honda CBR 150 CC:

1) Mempersiapkan peralatan untuk proses pengujian kapasitas radiator pada sistem Honda CBR $150 \mathrm{CC}$.

2) Memasang thermocouple masuk dan keluar pada radiator dan memasang alat ukur suhu digital thermocouple untuk mengetahui hasil pada saat pengujian.

3) Mengisi fluida (coolant water) ke radiator untuk persiapan uji coba.

4) Menghidupkan mesin untuk mensirkulasikan fluida didalam radiator. 
Analisis Pengaruh Laju Aliran Massa Fluida Terhadap Perubahan Temperatur Pada Radiator Honda CBR 150 CC

5) Melakukan 5 variasi RPM dan 5 variasi temperatur fluida masuk.

6) Melakukan pencatatan data laju aliran massa $(\dot{m})$ dengan melihat flow meter

7) Melakukan pencatatan temperatur fluida keluar $\left(T_{\text {out }}\right)$ dengan membaca digital thermocouple, untuk temperatur fluida masuk $\left(T_{\text {in }}\right)$ sudah disetting oleh peneliti.

8) Melakukan pengujian setiap variasi putaran mesin dengan berbagai variasi temperatur dan mencatat hasil selama pengujian.

9) Melakukan bertahap pada pengujian radiator dengan durasi waktu $+/-45$ menit dan proses pendinginan membutuhkan waktu +/- 5-10 menit.

D. Analisis

1) Massa fluida

Analisis yang dipergunakan sebagai penjelasan untuk perhitungan laju aliran massa di dalam radiator pada fluida air radiator menggunakan rumus sebagai berikut[3]:

$m=v \times p$

Keterangan:

$V \quad=$ Volume $\left(\mathrm{m}^{3}\right)$

$\dot{m} \quad=$ Laju aliran massa $(\mathrm{L} / \mathrm{m}=\mathrm{kg} / \mathrm{s})$

$\rho \quad=$ Massa Jenis $\left(\mathrm{Kg} / \mathrm{m}^{3}\right)$

2) Laju perpindahan panas

Analisis yang dipergunakan sebagai penjelasan untuk perhitungan laju perpindahan panas didalam radiator pada fluida air radiator menggunakan rumus sebagai berikut[3]:

$Q_{\text {in }}=m \times C p \times \Delta T$

Keterangan:

$\mathrm{Q}_{\text {in }} \quad=$ Laju perpindahan panas masuk $($ watt $=\mathrm{J} / \mathrm{s})$

$\rho \quad=$ Massa Jenis $\mathrm{kg} / \mathrm{m}^{3}$

$C p \quad=$ Kalor jenis $(\mathrm{j} / \mathrm{kg} . \mathrm{k})$

$\Delta T \quad=$ Perubahan suhu (kelvin

3) Menentukan koefisien perpindahan panas konveksi $(h)$.

Mencari nilai dari perpindahan panas konveksi dan menyederhanakan perhitungan maka menggunakan rumus[3]:

$h=\frac{N_{u} k}{L}$

Keterangan:

$\mathrm{L}=$ Karakteristik (Tebal Radiator)

$\mathrm{K}=$ Konduktivitas Termal Udara

4) Menentukan kapasitas penukar panas ( $\left.Q_{\text {out }}\right)$ 
Perpindahan panas konveksi $(h)$ dan nilai luas penampang perpindahan panas (A) telah diketahui, maka keduanya disubstitusikan ke dalam rumus[3].

$Q_{\text {out }}=h \times A\left(T_{f}-T_{\infty}\right)$

\section{HASIL DAN PEMBAHASAN.}

Berdasarkan hasil pengujian diperoleh nilai putaran (rpm), temperatur masuk $\left(T_{\text {in }}\right)$, massa fluida $(\dot{m})$, koefisien perpindahan panas $(h)$, laju perpindahan panas $\mathrm{Q}_{\text {in }}$ dan $\mathrm{Q}_{\text {out }}$ ditampilkan dalam bentuk tabel 1.

Tabel 1. Perbandingan nilai $\mathrm{Q}_{\text {in }}$ dan $\mathrm{Q}_{\text {out }}$ Pada Air radiator AHM

\begin{tabular}{|c|c|c|c|c|c|c|c|}
\hline NO & RPM & $\begin{array}{l}\text { Tin } \\
\left({ }^{\circ} \mathrm{C}\right)\end{array}$ & $\begin{array}{c}\mathbf{T}_{\mathbf{f}} \\
\left({ }^{\circ} \mathbf{K}\right)\end{array}$ & $\begin{array}{c}\dot{m} \\
(\mathrm{~kg} / \mathrm{s})\end{array}$ & $\begin{array}{c}h \\
\left(\mathrm{~W} / \mathbf{m}^{2} . \mathrm{K}\right)\end{array}$ & $\begin{array}{c}\mathbf{Q}_{\text {in }} \\
\text { Watt }\end{array}$ & $\begin{array}{c}\text { Q Qut } \\
\text { Watt }\end{array}$ \\
\hline \multirow{4}{*}{1} & & 90 & 310,5 & 27 & 113928,178 & 4989600 & 62714841,64 \\
\hline & 8000 & 100 & 318,5 & 54 & 110515,5978 & 8618400 & 118093983,9 \\
\hline & & 110 & 329 & 81 & 106307,845 & 9185400 & 185887133,8 \\
\hline & & 90 & 313 & 42 & 112838,1869 & 6879600 & 80383893,26 \\
\hline \multirow[t]{3}{*}{2} & 8500 & 100 & 324,5 & 84 & 108072,9265 & 9172800 & 157477924,5 \\
\hline & & 110 & 332 & 126 & 105175,878 & 11113200 & 204342006,3 \\
\hline & & 90 & 319 & 81 & 110309,3916 & 9185400 & 121445565,9 \\
\hline \multirow[t]{3}{*}{3} & 9000 & 100 & 328 & 162 & 106690,7004 & 12927600 & 179647081,6 \\
\hline & & 110 & 332,5 & 243 & 104989,5906 & 20412000 & 207379743,9 \\
\hline & & 90 & 323,5 & 108 & 108488,8308 & 8164800 & 151058003,7 \\
\hline \multirow[t]{3}{*}{4} & 9500 & 100 & 329 & 216 & 106307,845 & 15422400 & 185887133,8 \\
\hline & & 110 & 335 & 324 & 105714,8223 & 20412000 & 225928009,6 \\
\hline & & 90 & 325,5 & 150 & 107699,4479 & 8820000 & 163908543,7 \\
\hline \multirow[t]{2}{*}{5} & 10000 & 100 & 330 & 300 & 105927,7801 & 18900000 & 192082657,1 \\
\hline & & 110 & 336,5 & 450 & 103378,5484 & 22680000 & 230977553,5 \\
\hline
\end{tabular}

Berikut analisis hasil eksperimen berdasarkan perhitungan teoritis, dimana hubungan waktu (t) dengan $\left(\mathrm{Q}_{\text {in }}\right)$ terhadap putaran mesin $(\mathrm{rpm})$ seperti gambar 3.

Dari gambar 2. grafik dalam waktu 1 menit pada putaran 8000 rpm didapatkan temperatur masuk ( $\left.Q_{\text {in }}\right) 4989600$ watt terjadinya kenaikan temperatur dalam putaran 10000 rpm dengan temperatur masuk $\left(Q_{\text {in }}\right) 8820000$ watt. Sedangkan waktu 2 menit pada putaran 8000 rpm didapatkan temperatur masuk $\left(\mathrm{Q}_{\text {in }}\right) 8618400$ watt terjadinya kenaikan temperatur dalam putaran $10000 \mathrm{rpm}$ dengan temperatur masuk $\left(\mathrm{Q}_{\text {in }}\right) 18900000$ watt dan waktu 3 menit pada putaran 8000 rpm didapatkan temperatur keluar $\left(\mathrm{Q}_{\text {in }}\right) 9185400$ watt terjadinya kenaikan temperatur dalam putaran $10000 \mathrm{rpm}$ dengan temperatur keluar $\left(\mathrm{Q}_{\text {in }}\right) 22680000$ watt. 
Analisis Pengaruh Laju Aliran Massa Fluida Terhadap Perubahan Temperatur Pada Radiator Honda CBR 150 CC

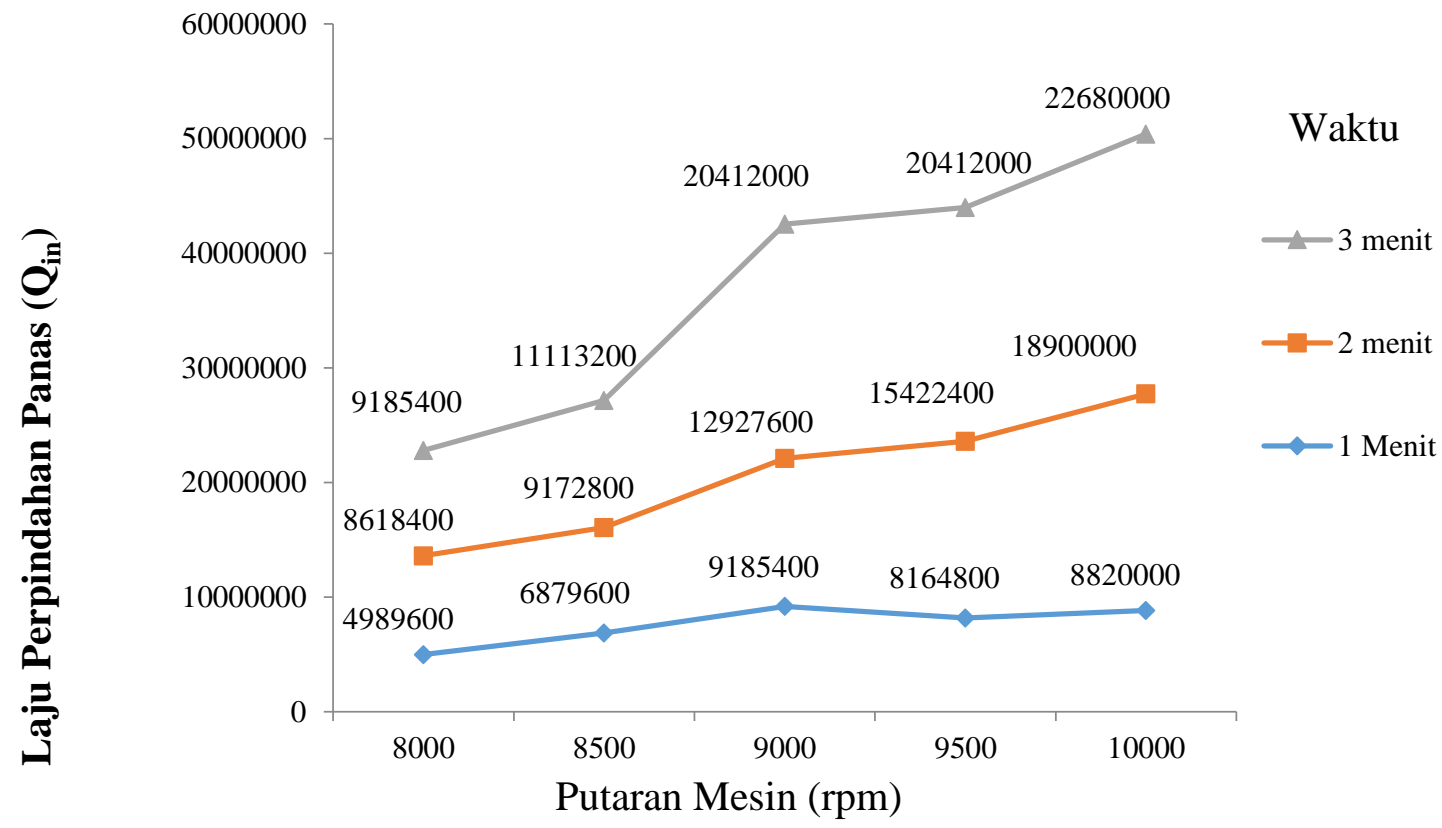

Gambar 2. Grafik waktu (t) dengan $\left(\mathrm{Q}_{\mathrm{in}}\right)$ terhadap putaran mesin $(\mathrm{rpm})$.

Hal ini menandakan semakin lama waktu berputarnya mesin, maka semakin tinggi laju perpindahan panas $\left(Q_{\text {in }}\right)$. Hal ini dikarenakan kenaikan $\mathrm{rpm}$ radiator bekerja lebih ekstra untuk mendinginkan mesin atau mempertahankan suhu mesin selalu berada di suhu operasional.

Berikut analisis hasil eksperimen berdasarkan perhitungan teoritis, dimana hubungan pengaruh $\left(\mathrm{T}_{\text {in }}\right)$ dengan $\left(\mathrm{Q}_{\text {out }}\right)$ terhadap putaran mesin $(\mathrm{rpm})$ seperti gambar 3.

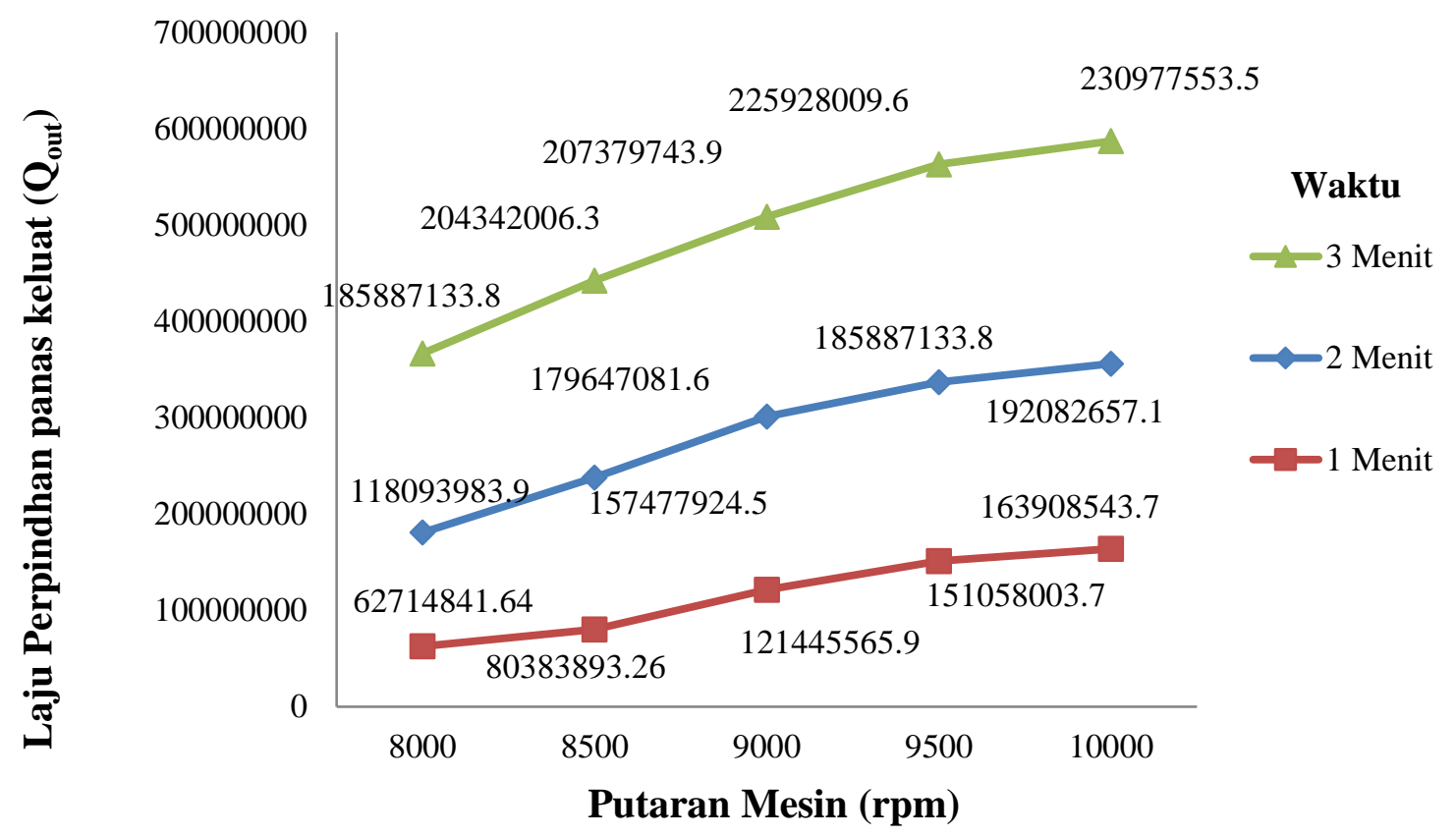

Gambar 3. Grafik waktu (t) dengan ( $\left.\mathrm{Q}_{\text {out }}\right)$ terhadap putaran mesin (rpm) 
Dari gambar 3 dapat dilihat bahwa grafik, dalam waktu 1 menit pada putaran $8000 \mathrm{rpm}$ didapatkan temperatur keluar ( $Q_{\text {out }}$ ) 62714841,61 watt terjadinya kenaikan temperatur dalam putaran 10000 rpm dengan temperatur keluar ( $\left.Q_{\text {out }}\right)$ 163908543,7 watt. Sedangkan waktu 2 menit pada putaran 8000 rpm didapatkan temperatur keluar ( $Q_{\text {out }}$ ) 118093983,9 watt terjadinya kenaikan temperatur dalam putaran 10000 rpm dengan temperatur keluar (Qout) 192082657,1 watt. Dalam waktu 3 menit pada putaran $8000 \mathrm{rpm}$ didapatkan temperatur keluar $\left(\mathrm{Q}_{\text {out }}\right)$ 185887133,8 watt terjadinya kenaikan temperatur dalam putaran 10000 rpm dengan temperatur keluar ( $Q_{\text {out }}$ ) 230977553,5 watt. Hal ini menandakan semakin lama waktu berputarnya mesin, maka semakin tinggi laju perpindahan panas $\left(\mathrm{Q}_{\text {out }}\right)$, dikarenakan kenaikan rpm radiator bekerja lebih ekstra untuk mendinginkan mesin atau mempertahankan suhu mesin selalu berada di suhu operasional.

\section{SIMPULAN}

Penggunaan coolant pada motor Honda CBR 150 CC dibuktikan dengan temperatur masuk dan keluar. Semakin rendah temperatur keluar maka semakin tinggi temperatur masuknya. Hal ini karena kinerja radiator masih maksimal, dalam waktu 1 menit pada putaran 8000 rpm didapatkan temperatur keluar (Qout) 62714841,61 watt terjadinya kenaikan temperatur dalam putaran $10000 \mathrm{rpm}$ dengan temperatur keluar ( $Q_{\text {out }}$ ) 163908543,7 watt. Sampai waktu 3 menit pada putaran 8000 rpm didapatkan temperatur keluar ( $\left.\mathrm{Q}_{\text {out }}\right)$ 185887133,8 watt terjadinya kenaikan temperatur dalam putaran $10000 \mathrm{rpm}$ dengan temperatur keluar ( $\left.Q_{\text {out }}\right)$ 230977553,5 watt. Hal ini menandakan semakin lama waktu berputarnya mesin, maka semakin tinggi laju perpindahan panas ( $\left.\mathrm{Q}_{\text {out }}\right)$, dikarenakan kenaikan rpm radiator bekerja lebih ekstra untuk mendinginkan mesin atau mempertahankan suhu mesin selalu berada di suhu operasional. Berdasarkan penggunaan alat uji untuk mengetahui pengaruh waktu, temperatur masuk dan keluar terhadap laju aliran motor Honda CBR 150 CC tidak terjadi overheating dikarenakan sistem pendingin radiator masih bisa mempertahankan suhu kerja mesin dalam waktu 1 menit pada putaran 8000 rpm didapatkan temperatur masuk $\left(Q_{i n}\right) 4989600$ watt terjadinya kenaikan temperatur dalam putaran 10000 rpm dengan temperatur masuk ( $\left.Q_{\text {in }}\right) 8820000$ watt. Sedangkan waktu 2 menit pada putaran 8000 rpm didapatkan temperatur masuk $\left(Q_{\text {in }}\right) 8618400$ watt terjadinya kenaikan temperatur dalam putaran $10000 \mathrm{rpm}$ dengan temperatur masuk $\left(\mathrm{Q}_{\text {in }}\right) 18900000$ watt dan waktu 3 menit pada putaran 8000 rpm didapatkan temperatur keluar $\left(Q_{\text {in }}\right) 9185400$ watt terjadinya kenaikan temperatur dalam putaran $10000 \mathrm{rpm}$ dengan temperatur keluar $\left(\mathrm{Q}_{\text {in }}\right) 22680000$ watt. Hal ini menandakan semakin lama waktu berputarnya mesin, maka semakin tinggi laju perpindahan panas $\left(\mathrm{Q}_{\text {in }}\right)$, dikarenakan kenaikan rpm radiator bekerja lebih ekstra untuk mendinginkan mesin atau mempertahankan suhu mesin selalu berada di suhu maksimal.

\section{REFERENSI}

[1] S. Lubis, I. Siregar, and A. M. Siregar, "FT-UMSU Jurnal Rekayasa Material, Manufaktur dan Energi FT-UMSU," Vol. 3, No. 2 Tek. Mesin, Fak. Tek. Univ. Muhammadiyah Sumatera 
Analisis Pengaruh Laju Aliran Massa Fluida Terhadap Perubahan Temperatur Pada Radiator Honda CBR 150 CC

Utara, vol. 3, no. 2, pp. 85-92, 2020.

[2] "EXHAUST SYSTEM GENERATOR: KNALPOT PENGHASIL LISTRIK DENGAN PRINSIP TERMOELEKTRIK," Sainteknol, vol. 13, no. 2, 2015, doi:

10.15294/sainteknol.v13i2.5249.

[3] A. Adi, "Analisa Pengaruh Laju Aliran Massa Fluida Dan Temperatur Fluida Masuk Terhadap Kapasitas Radiator Pada Sistem Pendingin Daihatsu Xenia 1300Cc,” J. Pendidik. Tek. Mesin UNESA, vol. 6, no. 03, p. 251623, 2018.

[4] D. R. Ariga, Maritas, and T. Sugiarto, "Pada Sistem Pendingin Air Terhadap Tingkat Panas Mesin Mobil Toyota," Perbandingan Pengguna. Aditif Pada Sist. Pendingin Air Terhadap Tingkat Panas Mesin Mob. Toyota Avanza 1,3 G M/T, 2015.

[5] A. Clifford, S. Darmawan, and A. Riza, "Analisis Kinerja Coolant Radiator," J. Tek. Mesin Univ. Tarumanegara, vol. 12, no. November, pp. 122-128, 2013.

[6] D. Amni and J. T. Otomotif, "Pengaruh Pelepasan Thermostat Terhadap Konsumsi Bahan Bakar Mesin Toyota Kijang 5K,” pp. 1-7, 2014.

[7] M. R. Murti, "Laju Pembuangan Panas Pada Radiator Dengan Fluida Campuran 80\% Air Dan 20\% Rc Pada Rpm Konstan,” J. Energi Dan Manufaktur, vol. 3, no. 1, 2012.

[8] J. Jaim, "ANALISIS PENGARUH JUMLAH SUDU WATER PUMP PADA MOBIL ' $X$ ' TERHADAP TERJADINYA OVERHEATING,” J. Tek. Mesin Cakram, vol. 2, no. 2, 2020, doi: $10.32493 /$ jtc.v2i2.4023.

[9] S. Paneliya, S. Khanna, U. Patel, P. Prajapati, and I. Mukhopadhyay, "Systematic investigation on fluid flow and heat transfer characteristic of a tube equipped with variable pitch twisted tape," Int. J. Thermofluids, vol. 1-2, 2020, doi: 10.1016/j.ijft.2019.100005.

[10] T. DARMA SETIAWAN and I. MADE ARSANA, "Pengaruh Kondisi Temperatur Dan Laju Aliran Massa Terhadap Kapasitas Radiator (Assy St-100) Mobil Suzuki Carry,” J. Pendidik. Tek. Mesin, vol. 7, no. 1, pp. 55-60, 2018.

[11] A. M. M. Ibrahim, B. R. Elhub, and H. A. A. Wahab, "Experimental study on heat transfer and fluid flow in vertical rifled," Adv. Mater. Res., vol. 505, no. December, pp. 524-533, 2012, doi: 10.4028/www.scientific.net/AMR.505.524.

[12] N. Nazilah and B. U. Kukuh Widodo, "Analisis Numerik Pengaruh Pitch Ratio Longitudinal (SL/2a) dan Transversal (ST/2b) 1, 1.25, dan 1.5 terhadap Karakteristik Aliran Fluida dan Perpindahan Panas melintasi Staggered Elliptical Tube Banks," J. Tek. ITS, vol. 5, no. 1, 2016, doi: 10.12962/j23373539.v5i1.15673.

[13] J. T. Mesin, F. Teknik, and U. Tadulako, “ANALISIS PENGARUH KUALITAS UAP RATARATA TERHADAP KOEFISIEN PERPINDAHAN PANAS RATA-RATA PADA PIPA KAPILER DI MESIN REFRIGERASI FOCUS 808 Basri,” vol. 2, no. 2, pp. 10-15, 2011. 
[14] H. -, W. Adriansyah, A. -, and A. D. Pasek, "Metodologi Perhitungan Koefisien Perpindahan Panas Konveksi Paksa Fluida Organik Propana Pada Kondisi Superkritik," J. Teknol., vol. 9, no. 2 , p. 89, 2017, doi: 10.24853/jurtek.9.2.89-96.

[15] C. Lin, J. Saunders, and S. Watkins, "The effect of changes in ambient and coolant radiator inlet temperatures and coolant flowrate on specific dissipation," SAE Tech. Pap., no. March 2000, 2000, doi: 10.4271/2000-01-0579. 